\title{
Emotioncy: a post-linguistic approach toward vocabulary learning and retention
}

\author{
Reza Pishghadam* and Shaghayegh Shayesteh \\ Department of English Language and Literature, Faculty of Letters and Humanities, Ferdowsi University of Mashhad, Mashhad, Iran.
}

\begin{abstract}
Inspired by the Developmental Individual-difference Relationship-based (DIR) model of first language acquisition and Emotion-Based Language Instruction (EBLI) in bilingual education, the current study explores the function of emotioncy as an effective benchmark for vocabulary teaching. In particular, it attempts to empirically extend the earlier work on emotioncy, investigate learners' vocabulary development, and draw a link between learners' emotioncy and their diverse socio-economic backgrounds. In order to do this, 45 English language learners were selected from schools located within various regions of Mashhad, Iran with high, mid and low socio-economic status. Thereafter, a list of 21 vocabulary items was taught to them during 4 successive sessions. At each session, 7 words were presented to the learners and finally their retention was examined by means of immediate and delayed tests. To analyse the data, MANOVA was run to detect the likely influence of emotioncy on learners' ability of vocabulary learning and retention. Subsequently, ANOVA was employed to determine the probable discrepancies among the three groups of learners. Lastly, Pearson Product Moment Correlation was utilised to investigate possible correlations between learners' tests and their level of emotioncy, English score and overall GPA. The findings indicated that learners from the high socio-economic class outperformed their counterparts from the mid or low social class, concluding that learners' economic/social/cultural capital significantly determines their degree of emotioncy. Furthermore, the learners' emotional competencies surpassed their cognitive abilities in accounting for their general vocabulary learning success. Finally, some suggestions and implications were provided within the realms of vocabulary learning and language education.
\end{abstract}

Keywords: Emotioncy, vocabulary, emotional capital, cultural capital, EBLI, DIR.

\section{INTRODUCTION}

There is a growing consensus among second/foreign language (L2/FL) experts that adequate lexical knowledge is an indispensable constituent of $\mathrm{L} 2 / \mathrm{FL}$ proficiency (Hafiz and Tudor, 1990; Horst et al., 1998). Modern research suggests that the meaning of words is the fundamental basis of learning a language; structure is considered as the second step (Bogaards, 2001; Kritikou et al., 2010; Nation, 1990). Hence, how words can best be learned has long been a major concern of several practitioners (e.g., Liu, 2013). Although mastering vocabulary may seem to be one of the most effortless aspects of L2/FL learning, it is, in essence, a challenging task. Apart from learners, teachers and educators might also experience numerous difficulties while attempting to improve learners' overall vocabulary knowledge in a way that yields better results. In fact, learners bring a broad range of individual differences to the language learning situation which strongly impacts the learning rate and the ultimate outcome. Given that learners are different and cannot be treated in a uniform fashion, different methods of teaching words are called for to target their idiosyncratic needs in various circumstances (Sokmen, 1997).

One primary question a language teacher is required to address is what type of vocabulary s/he should teach to ensure better learning on the part of learners and to make the learning process enjoyable to them. In response to this question, several criteria have been recommended by numerous experts in the field to help teachers make valid decisions regarding the right vocabulary to teach at every educational level; however, there is not one agreed upon set of criteria. From this perspective, Widdowson (1978; 1983) proposed that, depending on the context, frequency, valency and prototype are noteworthy criteria for vocabulary teaching. Likewise, availability (Wallace, 1988), learnability (McCarthy, 1990) and cultural factors (Gairns and Redman, 1989) have been referred to as sound selection criteria for vocabulary instruction.

An investigation of the distinct pedagogical techniques employed to select the particular words to be taught evidenced that these trends have gravitated towards individuals' cognitive diversities and social requirements. Yet, the study of learners' emotional 
diversities as a consistent predictor of learners' success have been neglected to a considerable extent. In order to fill this gap, recently, Pishghadam, Adamson et al. (2013) and Pishghadam, Tabatabaeyan et al. (2013) studied the type and degree of emotions different learners possess toward different words, claiming that these lexical emotions are conducive to in-depth word knowledge. Drawing upon Greenspan's Developmental, Individualdifference, Relationship-based (DIR) model of first language acquisition, Pishghadam, Tabatabaeyan et al. (2013) offered their new emotion-oriented approach in the realm of L2 education to reduce the burden of learning vocabulary by heeding the emotions learners carry over from their L1. Based on this approach, they introduced the technical term emotioncy, under the title of EmotionBased Language Instruction (EBLI), as a feature which can regulate the salience of a word for the goal of vocabulary teaching. Nevertheless, since this underresearched perspective has not been put into practice, this paper employs the conception in a larger framework and provide adequate empirical evidence on the application of emotioncy in the field of L2 vocabulary retention and presentation. To do so, the role of learners' socioeconomic status is prioritised, building on the notion that individuals coming from different regions, social classes and cultural backgrounds are possibly familiar with certain types of words and that certain words hold stronger emotions for them (Pishghadam, Tabatabaeyan et al., 2013). Bearing this in mind, first, it is investigated if emotioncy affects the vocabulary retention of learners from different socio-economic classes. Thereafter, the emotioncy scores, the learners provided for different types of vocabulary items were scrutinised. Finally, the impact of various external factors including emotioncy, overall GPA (which shows the overall ability of learners) and English score (as an indicator of the learners' general English ability) were compared to identify factor/s that account for enhanced vocabulary success.

\section{THEORETICAL FRAMEWORK}

\section{Vocabulary teaching}

Throughout the last two decades, the field of vocabulary learning and acquisition has been particularly productive and has been considered as one of the most controversial aspects in language acquisition and learning (Nation, 1990). Meanwhile, different strategies have been proposed to aid learners to acquire and remember words more effectively. In a broad sense, these techniques can be placed upon a continuum with its two extremes being meaningful or mechanical (Qian, 1996). Several L2 researchers provide evidence in support of meaningful learning and proper context to build vocabulary knowledge (Fischer, 1994; Nation and Wang, 1999). For instance, Krashen (1989) posits that meaning-focused reading results in vocabulary building. Similarly, semantic mapping, inference, or guessing techniques in which learners are required to use given contextual cues that might be helpful to arrive at the intended meaning (Oxford, 1990). However, Sokmen (1997) alleged that contextualised teaching is rather time-consuming and that it does not necessarily commit the words to long-term memory due to the lack of adequate repetition. Holding a mechanical perspective toward vocabulary learning, a number of L2 practitioners (e.g., Laufer, 2009; Qian, 1996) put forth counter-arguments that decontextualised vocabulary teaching strategies (such as mnemonic strategies, frequent rehearsals and paired-associate learning) are much more beneficial in comparison to the ones which employ words in various contexts. For instance, paired-associate learning (PAL), as one of the most popular methods of decontextualised vocabulary teaching, revolves around learning the translations and synonyms of foreign words. Although relevant findings indicate that PAL and similar strategies which eliminate the role of context, may lead to short-term vocabulary retention (Chun et al., 2012), it is believed that a constant keeping of the words in the short-term memory may facilitate their transfer to long term memory.

Whether meaningful or mechanical, teachers should be fully aware of why they select a particular strategy and determine which strategy is more effective during their cycle of teaching. Alongside adopting tools of proper pedagogical instruction, teaching carefully chosen words benefits students' vocabulary knowledge as well (Beck et al., 2002). Duffelmeyer and Duffelmeyer (1979) claimed that selecting words which are directly linked to the learners' experiences and needs may ease the process of vocabulary building. In this vein, several L2 practitioners (e.g., Campillo, 1995; Nation, 1990; Widdowson, 1978; 1983) provided different criteria for vocabulary teaching. Pioneered by the idea of frequency, it appeared to be entirely logical to teach the most frequent words of a language before the less frequent ones, as they may probably be the most productive words for learners of the language (Nation, 1990; Walter, 1995; Widdowson, 1978). Through a number of studies conducted to examine learners' free recall of a list of vocabulary items (e.g., DeLosh and MacDaniel, 1996; Gregg, 1976), it was concluded that learners were more successful in recalling high frequency words in comparison to low frequent ones. Yet, in another study, Ellis and Beaton (1993) reported a weak negative correlation between recall and frequency. Besides, word frequency was assumed to affect mainly productive knowledge (listening and reading) rather 
than perceptive knowledge (speaking and writing) (De Groot and Keijzer, 2000). To compensate for these deficiencies, Widdowson $(1983 ; 2004)$ came up with the notions of valency and prototype to emphasise the concept of language 'use'. Valency, as a process-oriented term for coverage (Mackey, 1965), is the potential of an item to generate further learning. Thus, teachers would tend to teach the meaning of a specific structure or word, since its acquisition provides the foundation for learners to understand and learn other structures and meanings. However, the frequency criterion still remains a substantial constituent of valency. Looking somewhat further, prototype was selected as a valid teaching criterion. Prototypes are words and structures that are likely to be included as pedagogically core at a specific stage with respect to their actual occurrence in contexts of use. Following this, several distinct criteria including availability (Wallace, 1988), learnability (McCarthy, 1990) and cultural factors (Gairns and Redman, 1989) were proposed to target different dimensions of vocabulary instruction; however, none gained any significant popularity.

\section{Emotioncy}

Since, according to Greenspan's (1992) DIR model, words possess an affective dimension, Pishghadam, Adamson et al. (2013) and Pishghadam, Tabatabaeyan et al. (2013) found it relevant to broach emotioncy as a potential criterion according to which words with a higher degree of emotional response are learned faster and more easily than words with lower emotional weight. For instance, between the words 'banana' and 'chopsticks', an African child learns 'banana' faster, since unlike 'chopsticks', he has touched, smelled and tasted banana. In this respect, they believe that, emotioncy, as the degree of emotional response towards different words, is potentially able to determine the salience of a word and serve the purpose of a worthwhile benchmark for vocabulary teaching. In essence, this viewpoint is the prominent constituent of EBLI. Largely inspired by Greenspan (1992) and his model of DIR, Pishghadam, Adamson et al. (2013) and Pishghadam, Tabatabaeyan et al. (2013) introduced EBLI to the domain of L2 education. The methodological core of the DIR framework is to underscore the role of affect and the importance of supportive relationships and family functioning (Greenspan, 1992). In a similar manner, Pishghadam, Tabatabaeyan et al. (2013) argued that, the critical missing link in the L2 acquisition domain may be found in the investment of affect. Indeed, children acquire their mother tongue while interacting emotionally with their parents. It implies that words have meanings and meanings are conveyed through the emotional context in which the word is used (Greenspan, 1992). Unlike the first language acquisition procedure where "word" (semantic aspect of language) and "world" (pragmatic aspect of language) are acquired simultaneously, during the process of L2 learning the child already possesses the "world" information carried over from L1 and merely lacks the relevant "word". Hence, children are likely to learn the words which are equivalent to their L1 vocabulary as a result of possessing prior emotional knowledge. In order to justify the delay in the process of language learning and acquisition, Pishghadam, Adamson et al. (2013) and Pishghadam, Tabatabaeyan et al. (2013) referred to inter-emotionality and discussed that, in addition to the flow which exists between the first and second language in terms of grammatical rules and lexicon, emotions move between the two languages constantly. This phenomenon functions in a way that when the emotional flow is from L1 to L2, learners have the "word" but lack its pertinent "world". Yet, when this emotional flow moves in the opposite direction (i.e. from L2 to L1), learners may lack both the "word" and the "world".

From this perspective, individuals coming from families of differing socio-economic statuses and cultural backgrounds may possess better affective familiarity with particular types of words. Thus, it is considered beneficial if one moves from pure contextualisation toward emotionalisation in language teaching. As Pishghadam, Adamson et al. (2013) and Pishghadam, Tabatabaeyan et al. (2013) believe, de-emotionalisation goes beyond de-contextualisation, since regardless of establishing an emotional connection with the text, learners are not able to fully comprehend it.

On the whole, we believe that, emotional engagement provides meaningfulness, which can facilitate the process of language learning in general and vocabulary learning in particular. Since the domain of vocabulary is a common concern of almost all language learners and teachers, and due to the fact that conventional vocabulary techniques have comprehensively satisfied neither learners' nor teachers' needs, the current study extends the earlier work on emotioncy by empirical means, sheds extra light on this new emotion-related strategy and offers an alternative option to language teachers to engage in emotional vocabulary teaching.

\section{Purpose of the Study}

Despite all the proposed selection criteria, the need to support building vocabulary is constantly felt. Ever since the recognition of emotional theories in the realm of education during the 1980s and 1990s, its reflections have been observed within various L2 trends (e.g., 
Goleman, 1995; Lozanov, 1978; Pishghadam, 2009). However, the field of L2/FL vocabulary instruction lacks the strategic application of this rudimentary concept. Thus, it is strongly assumed that the emotional selection of words might help narrow this gap.

The current paper seeks to answer the following questions:

1. Does emotioncy affect long-term and short-term vocabulary learning and retention of learners coming from unequal socio-economic status (high, mid and low)?

2. Do learners from high, mid and low socio-economic status give diverse emotioncy scores to different types of vocabulary items?

3. Are there any significant associations between vocabulary development, emotioncy, overall GPA and English score?

\section{METHODOLOGY}

\section{Participants}

The sample used in this study consisted of 45 English language learners studying at three different schools in Mashhad, a city in the Northeastern part of Iran. The schools were selected based upon the learners' economic background and residence. That is, the learners were selected from schools located within various regions of the city with high, mid and low socio-economic status. However, due to the fact that, for instance, a working class family is not necessarily a low-income one, great efforts were made to harmonise the learners' social and cultural capital with their socio-economic position. Out of three classes which had 30, 31, and 35 learners, respectively, 45 were chosen on account of their similar GPAs and final exam scores for English during the first semester. It must be mentioned that the schools and the three classes were selected randomly to satisfy some statistical prerequisites. To ensure homogeneity, ANOVA was used (GPA: $\mathrm{F}=15.1, \mathrm{P}<.05$, and English scores: $\mathrm{F}=13.5, \mathrm{P}<.05$ ). The participants were all 14-year-old boys studying in the eighth year of school. Since the participants were all minors, the research procedure was fully explained to children and their parents. Prior to commencing the research, parental permission was obtained alongside the agreement of the children to participate in the research project. The children were also informed that they could withdraw at any time. The reason behind selecting boys only, is due to the researchers' inability to enter girls' schools considering the Islamic ambiance of Iran. The schools were selected based upon the learners' economic background, living area, and their parents' educational level and occupations.

\section{Instruments}

To collect the required information, a list consisting of 50 words was given to the learners to figure out the words they already knew. Subsequent to checking with the learners' responses, known words were deleted and 21 were selected to be taught later (Appendix 1). Further, relevant flash cards were employed for teaching and testing the target words.

\section{Procedure}

Initially, 45 learners were chosen from 3 groups of high $(n=15)$, mid $(n=15)$ and low social class $(n=15)$ on the basis of their socio-economic background. Thereafter, the Farsi translations of the 21 selected words were presented to the learners as a test to measure their amount of emotioncy toward each. To explicate, the learners were supposed to rate the words based on the extent to which they had seen (1 point), seen and touched (2 points), and seen, touched and used (3 points) each item. The words with which the learners were not familiar at all were scored 0 . The following example illustrates this rating scale:

\section{Pineapple:}

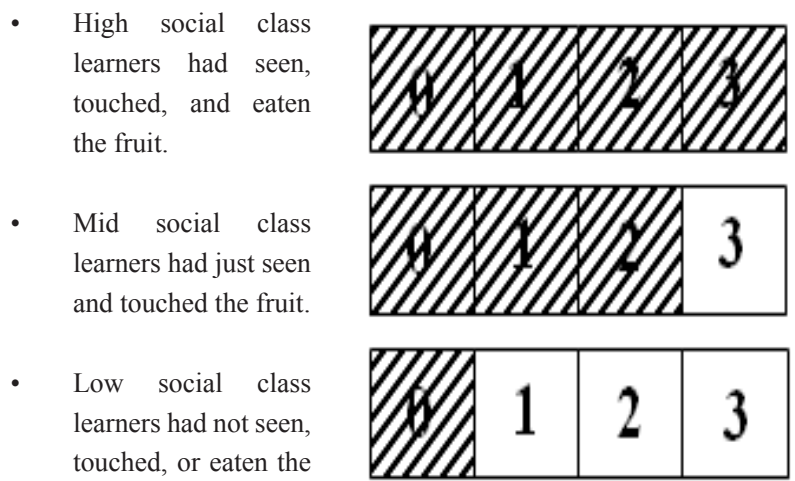
fruit.

Figure 1: Emotioncy level

The plan was to teach the 21 words over the course of 4 successive sessions. At each session, 7 words were presented to the learners by means of a series of flashcards. The reason behind choosing 7 words was to evaluate Miller's (1956) "magic 7, plus or minus two" in vocabulary teaching. It must be noted that, for the purpose of eliminating the effect of context, the words 
were taught to the learners out of context. To be specific, the teacher of each class was instructed formerly by one of the researchers concerning the items' teaching and testing procedure. During each class, twenty minutes were spent on teaching the words, while the rest of the class continued teaching according to their regular schedule.

Throughout 3 sessions, 21 words were taught to the learners of each group. Afterwards, during session 4, all 21 words were taught to the learners. By the end of session 4, the first test (using flashcards), named the 'Immediate' test, was administered to examine the learners' short-term vocabulary retention. Two weeks later, the learners' longterm ability to retrieve the words was checked by means of the second test, named the 'Delayed' test. Ultimately, the gathered data was entered into and analysed using SPSS 20 software. In the first place, MANOVA was run to investigate the probable influence of emotioncy on learners' ability of long-term and short-term vocabulary learning and retention with respect to their unequal socio-economic backgrounds. Afterwards, ANOVA was employed to identify the likely discrepancies among the three groups of learners in terms of their emotioncy level. Lastly, Pearson Product Moment Correlation was utilised to investigate the possible correlations between learners' immediate and delayed tests and their level of emotioncy, English score and overall GPA.

\section{RESULTS}

\section{Descriptive Statistics}

Table 1 demonstrates the descriptive statistics concerning the three groups of learners (High social class - Group 1 , Middle social class - Group 2 and Low social class Group 3) taking the two 'Immediate', 'Delayed' tests at different intervals.
Table 1: Descriptive statistics

\begin{tabular}{lrrrr}
\hline Test & Group & Mean & Std. Deviation & $\mathrm{N}$ \\
\hline Immediate & 1 & 15.80 & 2.85 & 15 \\
& 2 & 14.00 & 2.77 & 15 \\
& 3 & 9.40 & 1.40 & 15 \\
\multirow{4}{*}{ Delayed } & Total & 13.06 & 3.62 & 45 \\
& 1 & 13.53 & 2.66 & 15 \\
& 2 & 10.13 & 3.70 & 15 \\
& 3 & 7.60 & 3.43 & 15 \\
& Total & 10.42 & 4.05 & 45 \\
\hline
\end{tabular}

As the table suggests, Groups 1 and 3 carry the highest and lowest mean values respectively, which implies that, unlike the learners from the low class status who seem to display the lowest degree of emotioncy, individuals from the high class status possess the highest amount of emotioncy and have thus outperformed the other two groups.

In order to determine if the differences among the mean values are significant, multivariate tests (Pillai's Trace, Wilks' Lambda, Hotelling's Trace, Roy's Largest Root) were applied to the data. The results revealed that the differences among the means are statistically significant (Table 2).

\section{MANOVA}

MANOVA was run in order to explore if emotioncy leads to any significant differences between the learners' result of immediate and delayed tests. A close investigation of Table 3 displays that learners performed significantly better in the immediate test $(\mathrm{F}=27.45, \mathrm{p}<0.01)$ compared to the delayed one $(\mathrm{F}=12.21, \mathrm{p}<0.01)$. The table also reveals that, learners' degree of emotions accounts for $56 \%$ of the variance in the immediate test (Partial Eta Squared $=.56)$ and $36 \%$ of the variance in the delayed test (Partial Eta Squared=.36).

Table 2: Multivariate tests for the significance of the differences among means variables

\begin{tabular}{llrrrrrr}
\hline Effect & & Value & F & $\begin{array}{r}\text { Hypothesis } \\
\text { df }\end{array}$ & Error df & $\begin{array}{r}\text { Sig. } \\
\text { Partial Eta } \\
\text { Squared }\end{array}$ \\
\hline Intercept & Pillai's Trace & .97 & 772.11 & 2.00 & 41.00 & .00 & .97 \\
& Wilks' Lambda & .02 & 772.11 & 2.00 & 41.00 & .00 & .97 \\
& Hotelling's Trace & 37.66 & 772.11 & 2.00 & 41.00 & .00 & .97 \\
& Roy's Largest Root & 37.66 & 772.11 & 2.00 & 41.00 & .00 & .97 \\
Group & Pillai’s Trace & .67 & 10.62 & 4.00 & 84.00 & .00 & .33 \\
& Wilks' Lambda & .35 & 13.80 & 4.00 & 82.00 & .00 & .40 \\
& Hotelling's Trace & 1.71 & 17.17 & 4.00 & 80.00 & .00 & .46 \\
& Roy's Largest Root & 1.66 & 35.04 & 2.00 & 42.00 & .00 & .62 \\
\hline
\end{tabular}


Table 3: Results of multivariate tests

\begin{tabular}{lrrrrrr}
\hline Source & $\begin{array}{r}\text { Dependent } \\
\text { Variable }\end{array}$ & $\begin{array}{r}\text { Type III Sum } \\
\text { of Squares }\end{array}$ & df & Mean Square & $\begin{array}{r}\text { F } \\
\text { Partial Eta } \\
\text { Squared }\end{array}$ & $\begin{array}{r}\text { Sig. } \\
\text { Group }\end{array}$ \\
& Immediate & 326.80 & 2 & 163.40 & 27.45 & .00 \\
& Delayed & 265.91 & 2 & 132.95 & 12.21 & .00 \\
\hline
\end{tabular}

Since MANOVA demonstrates a significant difference between the pair of tests, post hoc Scheffe's tests were carried out to pinpoint the locations of the differenses. Table 4 summarises the results.

Table 4: Results of Post Hoc Scheffe's Test for 'Immediate'

\begin{tabular}{lrrr}
\hline Group & $\mathrm{N}$ & 1 & Subset \\
\hline 3 & 15 & 9.40 & \\
2 & 15 & & 14.00 \\
1 & 15 & & 15.80 \\
Sig. & & 1.0 & .14 \\
\hline
\end{tabular}

As seen in Table 4, learners in a Group 1 (high social class) $(\mathrm{M}=15.80)$ and Group 2 (mid social class) $(\mathrm{M}=14.00)$ performed better than their counterparts in Group 3 (low social class) $(\mathrm{M}=9.40)$ on the immediate test.

\begin{tabular}{lcrr} 
Table 5: Results of Post Hoc Scheffe's Test for 'Delayed' \\
\hline Group & N & \multicolumn{3}{r}{ Subset } \\
\hline 3 & 15 & 7.60 & \\
2 & 15 & 10.13 & \\
1 & 15 & & 13.53 \\
Sig. & & .12 & 1.00 \\
\hline
\end{tabular}

In correspondence with the results on the immediate test, Table 5 exhibits that, learners in Group $1(\mathrm{M}=13.53)$ surpassed their counterparts in Group $2(\mathrm{M}=10.13)$ and Group $3(M=7.60)$ on the delayed test. It indicates that high class learners performed better than the mid and low class learners.

\section{ANOVA}

To further analyse the data and examine the amount of emotion each group of learners assign to the words, ANOVA was employed. Table 6 reveals a significant difference among the three groups of learners with regard to the emotioncy scores they gave to the 21 targeted words $(\mathrm{F}=18.31, \mathrm{p}<0.01)$.
Further, to pinpoint the areas of differences among the three groups, the Scheffe's Post Hoc Test was run for emotioncy scores (Table 7).

\begin{tabular}{ccrr} 
Table 7: Results of Post Hoc Scheffe's Test for 'Emotioncy' \\
\hline Group & $\mathrm{N}$ & \multicolumn{2}{c}{ Subset for alpha $=0.05$} \\
& 15 & 35.00 & 2 \\
\hline 3 & 15 & & 46.20 \\
2 & 15 & & 53.13 \\
1 & & 1.00 & .08 \\
Sig.
\end{tabular}

Based on the Table 7, Group $1(\mathrm{M}=53.13)$ returned the highest emotioncy scores for the list of words, implying that they were more emotionally familiar with the vocabulary items. The second group $(\mathrm{M}=46.20)$ received the second lowest ranking and the third group $(\mathrm{M}=35.00)$ received the lowest ranking in emotioncy rating. Therefore, the learners from the high and mid class groups were better emotionally acquainted with the intended words than the individuals from the low class group.

\section{Correlation}

In order to answer the last research question, the Pearson Product Moment Correlation was run to see if there is any significant relationship between learners' immediate and delayed test results with respect to their emotioncy, English score and overall GPA. Table 8 summarises the results.

Table 8: The results of Correlational Analysis between the two tests with respect to external factors

\begin{tabular}{lrrr}
\hline & English Score & GPA & Emotioncy \\
\hline Immediate & .28 & .05 & $.35^{*}$ \\
Delayed & .26 & -.08 & $.43^{* *}$ \\
\hline
\end{tabular}

* Correlation is significant at the 0.05 level

** Correlation is significant at the 0.01 level

Table 6: Results of One-way ANOVA for emotioncy

\begin{tabular}{lrrrrr}
\hline & Sum of Squares & df & Mean Square & F & Sig. \\
\hline Between Groups & 2511.64 & 2 & 1255.82 & 18.31 & .00 \\
Within Groups & 2880.13 & 42 & 68.57 & & \\
Total & 5391.77 & 44 & & & \\
\hline
\end{tabular}


The correlational analysis indicates that there is a relatively moderate correlation between immediate $(\mathrm{r}=.35, \mathrm{p}<0.05)$ and delayed $(\mathrm{r}=.45, \mathrm{p}<0.01)$ test results with regards to emotioncy. In other words, the higher the emotioncy level, the better the learners perform on both immediate and delayed tests. Moreover, the statistical values suggest that the association between emotioncy and the delayed test is to some extent higher than the one with the immediate test. It implies that learners can possibly retrieve more words on the delayed test compared to the immediate one. Finally, there is no significant correlation between the test results and the learners' English score or overall GPA.

\section{DISCUSSION}

As already mentioned, selecting words for instructional purposes can and should be based on specific criteria (Sokmen, 1997), such as frequency, prototype and valency. However, in this study, we sought to examine whether the newly-proposed notion of emotioncy can account for learners' improved vocabulary learning and establish a relationship between emotioncy and socioeconomic class. Secondly, the emotioncy scores were studied to investigate the probable differences between learners of different social classes. Finally, the learners' vocabulary learning ability was correlated with their emotioncy level, general learning ability (GPA), and English ability (English score) to identify factors that explain the learners' general vocabulary knowledge development.

The primary results indicated that learners from the high socio-economic class outdid the ones from the mid and low social classes. This suggests that the degree of vocabulary learning diminishes as the learners move from high to low social class. These results are to a great extent in congruence with those of McLloyd (1998) and Hart and Risley (1995) who claimed that the rate of vocabulary development in children from the 'professional' background is faster than that of the ones from the 'working class'. Building upon the notion that possessing sufficient emotional information about the word is crucial to understanding its meaning (Pishghadam, Tabatabaeyan et al., 2013), one possible line of explanation may be that, thanks to their social and cultural capital, high class learners often have access to a wider range of L1 vocabulary items and take advantage of this richer emotional knowledge. Therefore, they learn the words more effectively than their counterparts in the other two groups.

With respect to the first aim of the study, it was revealed that, the learners outdid the immediate test compared to the delayed one with regard to the emotioncy scores. The probable explanation may be that, in a general sense, new information is held within the working memory as long as it is anchored to the existing information to be incorporated into the permanent memory (Stevick, 1996). Therefore, logically, the immediate test, which examines learners' short-term retention, may function better than the delayed test. Quite analogous to this claim, Anderson and Jordan (1928) reported a notable retention decline from week 1 to week 8 following the initial exposure. By the same token, once the new lexical items are stored in the permanent memory, usually a linguistic or situational context is required to trigger retrieval (Stevick, 1996). Hence, another likely reason for the learners' rather weak performance on the delayed test may be that our tests were designed to check the words in a decontextualised manner; thus, the stimulation might not have been satisfactory enough to get the desired result. Also, based on the Scheffe's tests, among the three groups of learners, individuals from the high and mid social class surpassed the low class learners on the immediate test. That is to say, those learners were able to make a number of greater and stronger connections with the list of presented words owing to their more extensive emotional lexical background knowledge. With regard to the delayed test, learners with high social status performed better than their counterparts with mid and low social status. A noteworthy point is that, scrutinising the result of the immediate test, the mid class learners were coupled with the high class ones; while, on the delayed test this group of learners joined the low class individuals. The overall conclusion may be that access to cultural and social capital brings about emotioncy. In other words, the more the learners ascend the socio-economic status ladder, the better they learn and retrieve vocabulary items. This outcome is quite compatible with the claims made by Bourdieu (1986) regarding the unequal scholastic achievement of children originating from the different social classes. Additionally, in the L2 domain, Pishghadam and Zabihi (2011) reported that learners with higher levels of social and cultural capital enjoy higher levels of language proficiency and educational achievement in general.

Regarding the second objective of the study, there was a significant difference between learners of different social classes in terms of the lexical emotioncy scores they assigned to the vocabulary items. The results actually indicated that learners from the high and mid socioeconomic class assigned higher emotioncy scores to the words, which typically depicts their stronger emotional connections with the vocabulary items. One probable rationale might be that opportunity and accessibility to cultural heritage presumably operate as a severe barrier for the low class learners which indeed accounts for their 
lack of adequate emotional value. Higher distribution of cultural and social capital among a given social class is an indicator of power, defining the chances of exclusive advantage in a particular field (Bourdieu et al., 1996). Hence, social inequalities alongside cultural capital previously invested by the families, significantly determine the learners' possession of lexical emotions.

Considering the third goal of the study, it was found that, learners' performance on both immediate and delayed tests correlated best with their emotioncy level, rather than their English score or overall GPA. From this perspective, a possible reason for the learners' educational attainment is not only their linguistic or cognitive abilities (English score or GPA) as suggested by different experts of the field (Ausubel, 1965; McLaughlin, 1987); it is in considerable part the result of emotional competencies. Building upon Ausubel's (1965) assumption of 'relatability', it can be declared that, emotional relatability is as crucial as cognitive relatability. An additional conclusion which may be drawn from this correlational analysis is that, unlike MANOVA, the correlational value of the delayed test stands somewhat higher than the one for the immediate test. To be specific, MANOVA verified the performance of each single group of learners, whereas the correlational analysis was run considering the total number of the participants. A likely justification may be that, in general, after a short period of time learners are better able to form emotional connections and associations with the already established emotional entities, which eventually contributes to their improved retention. Based on Nation's (1990) idea, association (quality) is more efficient than sheer repetition (quantity) in terms of vocabulary learning. The author's viewpoint can also be supported by the fact that the final aim in teaching vocabulary is not immediate retention; rather, it is the delayed retention of words that has educational value (Cohen, 1987).

\section{CONCLUSION}

Although further studies are required to substantiate the practical implementation and findings of the current study, the picture that emerges from the present study is clear: Emotioncy is a potential factor that could lead to increased vocabulary learning and retention. The obtained results can be interpreted as having some implications for more effective education especially in class-divided societies. Firstly, L2/FL material developers and syllabus designers are advised to be highly cautious in selecting and adapting different instructional resources and particularly coursebooks to reflect multiple perspectives reflective of a pluralistic society. Manifestly, misrepresentation brings about a biased approach towards a specific social/cultural class of the learners. It is recommended that educators take into account different learners' emotional backgrounds and maintain a balance between individuals' diverse cultures and affective life experiences. In this regard, once again, the viability of one-size-fits-all policy (Pishghadam and Mirzaee, 2008) becomes debatable. In order to achieve enhanced results, the textbooks could be localised for each social class to be better represented and to combat prejudices against the neglected working class. Thus, the fallacy that academic success or failure is a consequence of natural aptitude and students from higher socio-economic classes are often smarter, may be questioned. In turn, it is believed that, educational investment integrated with emotional capital enriches learners' academic development. An additional implication may address language teachers to enhance their awareness of their learners' emotions and employ a variety of resources to provide them with more inclusive instruction. Further, it is recommended that teachers thoughtfully establish the required emotional network of the lexical items they think the learners may not be familiar with prior to their teaching according to their planned schedule.

On the whole, it is important to bear in mind that teaching vocabulary is an influential means of language learning. Thus, this study hopes to serve as one of the preliminary steps towards a better understanding of this field. The findings should be considered a step forward for many L2 teachers and their students who tend to practice emotioncy over other conventional criteria to build vocabulary, hoping to give the learners a richer sense of a word's use and meaning. Nonetheless, readers must keep in mind that a study such as the present one has its own limitations. First, the current research did not have a large enough sample size for an experimental study. The results could have been more valid with a larger and appropriately targeted sample. Second, the sample participants consisted of only teenage males, making it difficult to generalise our findings to all language learners. Thus, universal generalisation of the findings is not recommended; yet, the implication of the data might be useful for similar contexts and samples.

Finally, the outcome of the study adds weight to the argument of vocabulary teaching and learning by suggesting that emotioncy is an undiscovered vocabulary dimension. Our findings could further be compared and contrasted with the retention power of different vocabulary presentation strategies to investigate the 
effectiveness of emotioncy in greater detail. Emotioncy could also be implemented and inspected in other subjects of schools such as mathematics and history.

\section{ACKNOWLEDGEMENTS}

The authors wish to express their sincere gratitude to the editor and anonymous reviewers of this manuscript who assisted us to fine-tune the paper. We give our special thanks to the participants who willingly took part in this study.

\section{REFERENCES}

Anderson, J. P. \& Jordan, A. M. (1928) Learning and retention of Latin words and phrases. Journal of Educational Psychology. 19. pp: 485-496. DOI: http://dx.doi.org/10.1037/h0073011

Ausubel, D. (1965) A cognitive structure view of word and concept meaning. In R. C. Anderson \& D. Ausubel (eds.). Readings in the psychology of cognition. pp: 103-115. New York: Holt, Rinehart and Winston.

Beck, I. L., McKeown, M. G. \& Kucan, L. (2002) Bringing words to life: robust vocabulary instruction. New York: Guilford.

Bogaards, P. (2001) Lexical units and the learning of foreign language vocabulary. Studies in second language acquisition. 23. pp: 321-343. DOI: http://dx.doi.org/10.1017/S0272263101003011

Bourdieu, P. (1986) The forms of capital. In J. G. Richardson (ed.). Handbook for theory and research for the sociology of education. pp: 241-258. New York: Greenwood Press.

Bourdieu, P., Passeron, J. \& Martin, M. S. (1996) Academic discourse: linguistic misunderstanding and professorial power. California: Stanford University Press.

Campillo, R. M. L. (1995) Teaching and learning vocabulary: an introduction for English students. Ensayos. 10. pp: 35-49.

Chun, E., Choi, S. \& Kim, J. (2012) The effect of extensive reading and paired-associate learning on long-term vocabulary retention: an event-related potential study. Neuroscience Letters. 521. pp: 125-129.

DOI: http://dx.doi.org/10.1016/j.neulet.2012.05.069

Cohen, A. D. (1987) The use of verbal and imagery mnemonics in second-language vocabulary learning. Studies in second language acquisition. 9. pp: 43-62.

DOI: http://dx.doi.org/10.1017/S0272263100006501

De Groot, A. \& Keijzer, R. (2000) What is hard to learn is easy to forget: the roles of word concreteness, cognate status and word frequency in foreign language learning and forgetting.
Language Learning. 50(1). pp: 1-56.

DOI: http://dx.doi.org/10.1111/0023-8333.00110

De Losh, E. \& McDaniel, M. (1996) The role of order information in free recall: application to the word-frequency effect. Journal of Experimental Psychology: Learning, Memory and Cognition. 22. pp: 1136-1146.

DOI: http://dx.doi.org/10.1037/0278-7393.22.5.1136

Duffelmeyer, F. \& Duffelmeyer, B. (1979) Developing vocabulary through dramatization. Journal of Reading. 23(2). pp: 141-43.

Ellis, N. \& Beaton, A. (1993) Factors affecting the learning of foreign language vocabulary: imagery keyword mediators and phonological short-term memory. The Quarterly Journal of Experimental Psychology. 46A(3). pp: 533-558.

DOI: http://dx.doi.org/10.1080/14640749308401062

Fischer, U. (1994) Learning words from context and dictionary: an experimental comparison. Applied Psycholinguistics. 15. pp: 551-574.

DOI: http://dx.doi.org/10.1017/S0142716400006901

Gairns, R. \& Redman, S. (1989) Working with words. A guide to teaching and learning vocabulary. Cambridge: Cambridge University Press.

Goleman, D. (1995) Emotional intelligence. New York: Bantam Books.

Greenspan, S. I. (1992) Infancy and early childhood: the practice of clinical assessment and intervention with emotional and developmental challenges. Madison, Connecticut: International Universities Press.

Gregg, V. (1976) Word frequency, recognition and recall. In J. Brown (ed.). Recall and recognition. pp: 183-216. Oxford, England: John Wiley \& Sons.

Hafiz, F. M. \& Tudor, I. (1990) Graded readers as an input medium in L2 learning. System. 18. pp: 31-42.

DOI: http://dx.doi.org/10.1016/0346-251x(90)90026-2

Hart, B. \& Risley, T. (1995) Meaningful differences in the everyday experiences of young American children. Baltimore: Brookes.

Horst, M., Cobb T. \& Meara, P. (1998) Beyond a clockwork orange: acquiring second language vocabulary through reading. Reading in a Foreign Language. 11. pp: 207-233.

Krashen, S. (1989) We acquire vocabulary and spelling by reading: additional evidence for the input hypothesis. Modern Language Journal. 73. pp: 440-464.

DOI: http://dx.doi.org/10.1111/j.1540-4781.1989.tb05325.x

Kritikou, Y., Stavroulaki, V., Paradia, M. \& Demestichas, P. (2010) User-oriented web-based learning management systems for enhanced vocabulary teaching. Procedia Social and 
Behavioral Sciences. 9. pp: 473-479.

DOI: http://dx.doi.org/10.1016/j.sbspro.2010.12.183

Laufer, B. (2009) Second language vocabulary acquisition from language input and from form-focused activities. Language Teaching. 42. pp: 341-354.

DOI: http://dx.doi.org/10.1017/S0261444809005771

Liu, Y. (2013) Toward a comprehensive model of foreign language vocabulary learning: to integrate instructed learning with incidental learning. Asian Social Science. 9(10). pp: 142150.

DOI: http://dx.doi.org/10.5539/ass.v9n10p142

Lozanov, G. (1978) Suggestology and outlines of suggestopedy. Philadelphia, Pennsylvania: Gordon \& Breach.

DOI: http://dx.doi.org/10.4324/9780203392829

MacCarthy, M. (1990) Vocabulary. Oxford: Oxford University Press.

Mackey, W. F. (1965) Language teaching analysis. London: Longman.

McLaughlin, B. (1987) Theories of second language learning. London: Edward Arnold.

McLloyd, V. C. (1998) Socioeconomic disadvantage and child development. American Psychologist. 53. pp: 185-204.

DOI: http://dx.doi.org/10.1037/0003-066X.53.2.185

Miller, G. (1956) The magical number seven, plus or minus two: some limits on our capacity for processing information. The Psychological Review. 63. pp: 81-97.

DOI: http://dx.doi.org/10.1037/h0043158

Nation, I. S. P. \& Wang, M. K. (1999) Graded readers and vocabulary. Reading in a Foreign Language. 12. pp: 355-380.

Nation, I. S. P. (1990) Teaching and learning vocabulary. New York: Newbury House.

Oxford, R. L. (1990) Language learning strategies: what every teacher should know. Boston: Newbury House.

Pishghadam, R., Adamson, B. \& Shayesteh, S. (2013) Emotionbased language instruction (EBLI) as a new perspective in bilingual education. Multilingual Education. 3(9). pp: 1-16.

DOI: http://dx.doi.org/10.1186/2191-5059-3-9

Pishghadam, R. \& Mirzaee, A. (2008) English language teaching in postmodern era. TELL. 2. pp: 89-109.

Pishghadam, R. \& Zabihi, R. (2011) An application of a questionnaire of social and cultural capital to English language learning. English Language Teaching. 4(3). pp: 21-29.

DOI: http://dx.doi.org/10.5539/elt.v4n3p151

Pishghadam, R. Tabatabaeyan, M. S. \& Navari, S. (2013).A critical and practical analysis of first language acquisition theories: The origin and development. Mashhad, Iran: Ferdowsi University of Mashhad Publications.

Pishghadam, R. (2009) A quantitative analysis of the relationship between emotional intelligence and foreign language learning. Electronic Journal of Foreign Language Teaching. 6(1). pp: 31-41.

Qian, D. D. (1996) ESL vocabulary acquisition: contextualization and decontextualization. Canadian Modern Language Review. 53. pp: 120-142.

Sokmen, A. J. (1997) Current trends in teaching second language vocabulary. In N. Schmitt \& M. McCarthy (eds.). Vocabulary: description, acquisition and pedagogy. pp: 237257. Cambridge: Cambridge University Press.

Stevick, E. W. (1996) Memory, meaning and method: a view of language teaching. Boston: Heinle \& Heinle.

Wallace, M. (1988) Teaching vocabulary. Oxford: Heinemann.

Walter, E. (ed.) (1995) Cambridge word selector. Cambridge: Cambridge University Press.

Widdowson, H. G. (1983) Learning purpose and language use. Oxford: Oxford University Press.

Widdowson, H. G. (1978) Teachinglanguage as communication. Oxford: Oxford University Press.

Widdowson, H. G. (2004) Text, context, and pretext: critical issues in discourse analysis. Oxford: Blackwell.

DOI: http://dx.doi.org/10.1002/9780470758427

\section{APPENDIX 1}

Words toward which different groups of learners have stronger emotioncy.

\section{Students from High Class}

$\begin{array}{ll}\text { Pineapple } & \text { Shorts } \\ \text { Peanut } & \text { Hostess } \\ \text { Pet } & \text { Gym }\end{array}$

Pie

Students from Mid Class

Sofa

Subway

Almond

Porcelain

Iron

Magazine

Keyboard

Students from Low Class

Pebble

Furnace

Hunger

Shoemaker
Brick

Wrench

Hammer 